\title{
Familiarity Does Indeed Promote Attraction in Live Interaction
}

\author{
Harry T. Reis, Michael R. Maniaci, \\ and Peter A. Caprariello \\ The University of Rochester
}

\author{
Paul W. Eastwick \\ Texas A\&M University
}

\author{
Eli J. Finkel \\ Northwestern University
}

\begin{abstract}
Does familiarity promote attraction? Prior research has generally suggested that it does, but a recent set of studies by Norton, Frost, and Ariely (2007) challenged that assumption. Instead, they found that more information about another person, when that information was randomly selected from lists of trait adjectives, using a trait evaluation paradigm, promoted perceptions of dissimilarity and, hence, disliking. The present research began with the assumption that natural social interaction involves contexts and processes not present in Norton et al.'s research or in the typical familiarity experiment. We theorized that these processes imply a favorable impact of familiarity on attraction. Two experiments are reported using a live interaction paradigm in which two previously unacquainted same-sex persons interacted with each other for varying amounts of time. Findings strongly supported the "familiarity leads to attraction" hypothesis: The more participants interacted, the more attracted they were to each other. Mediation analyses identified three processes that contribute to this effect: perceived responsiveness, increased comfort and satisfaction during interaction, and perceived knowledge.
\end{abstract}

Keywords: familiarity, attraction, relationship development, friendship formation

Among the core concepts of interpersonal attraction is the principle of familiarity. According to Berscheid and Regan (2005), for example, "the familiarity principle of attraction is perhaps the most basic of the [general principles of attraction]" (p. 177). Similarly, Ebbesen, Kjos, and Konecni (1976) concluded that "most positive interpersonal relationships result from frequent face-to-face contacts" (p. 505). These conclusions follow from the many studies, both correlational and experimental, that have supported a link between familiarity-defined as the degree of exposure that one person has to another person-and attraction to other persons. Consistent with this definition, the familiarity effect on attraction is typically explained in terms of the mere exposure effect (Zajonc, 1968, 2001) - that repeated exposure to a stimulus increases liking for that stimulus-although, as we discuss later,

This article was published Online First March 7, 2011

Harry T. Reis, Michael R. Maniaci, and Peter A. Caprariello, Department of Clinical and Social Sciences in Psychology, The University of Rochester; Paul W. Eastwick, Department of Psychology, Texas A\&M University; Eli J. Finkel, Department of Psychology, Northwestern University.

Preparation of this article was partly supported by a grant from the Fetzer Institute. We thank the following individuals for their assistance in conducting this research: Eric Anicich, Igua Benjamin, Stacy Congdon, Avi Dressler, Malorie Elmer, Arielle Friedlander, Beth Kacel, Molly Korotkin, Jacquie Kramer, Sarah Mancuso, Aquella Robinson, Ali Rosenbluth, Samantha Siskind, Penelope Spicer, Max Sutton-Smolin, and Jo Ellyn Walker.

Correspondence concerning this article should be addressed to Harry T. Reis, Department of Clinical and Social Sciences in Psychology, The University of Rochester, Box 270266, Rochester, NY 14627. E-mail: reis@psych.rochester.edu we believe that familiarity effects in social interaction involve more interpersonal processes.

A recent article by Norton, Frost, and Ariely (2007) challenged this conclusion. These authors proposed that familiarity tends to breed dislike, because familiarity, which they defined as acquiring more information about another person and typically operationalized in terms of acquiring random bits of information about that person, is likely to disconfirm assumptions about another person's similarity to oneself. Ambiguity, on the other hand, which they defined as the absence of information, was said to breed liking, because it facilitates the assumption that the other is similar to oneself, which makes it easier to imagine liking the other. Their article reported a series of clever experiments (described below) that supported their reasoning.

The present article is based on our belief that although Norton et al.'s (2007) findings may be internally valid, they misrepresent the typical operation of familiarity in acquaintanceship based on live interaction. That is, their model and research defines and operationalizes familiarity in terms of the amount of information that one has about another person. Although the acquisition and assessment of information is surely part of developing acquaintanceships, we propose that increasing familiarity in interactive relationships is a considerably more complex process, involving responsive interaction and affective experience, as well as other forms of interpersonal influence (Kelley et al., 1983). Moreover, their study presented information to participants that had been selected randomly from lists of positive and negative traits. As discussed below, we suspect that this is not representative of information exchange in real-world social interaction. Finally, we propose that knowledge gained about another person is assimilated and interpreted differently when it is acquired in the ebb-and-flow of interaction than when it is acquired acontextually. 
Norton et al.'s (2007) research used paradigms that are relatively similar to previous experiments on familiarity, in the sense that information was presented to participants in a very decontextualized manner. To our knowledge, no experiments have examined the "familiarity-leads-to-attraction" effect in contexts involving actual interaction; most experiments have followed the example of mere exposure studies, presenting stimuli such as names, faces, or trait information at varying frequencies. (Familiarity effects have been examined in natural settings [e.g., Berg, 1984; Shook \& Fazio, 2008], as described below, but because none of these studies were true experiments, their interpretations are potentially ambiguous.) There is an important distinction, we believe, between trait evaluation paradigms, in which participants evaluate static information about a person they will never meet, and live interaction paradigms, in which people interact in real time, acquire information contextually, and both evaluate and are evaluated by the partner. In other words, natural interaction differs in several important respects from thinking critically about lists of information. In fact, existing evidence suggests that information may be processed differently - that is, more holistically-when it is embedded in the ebb and flow of natural interaction. For example, in two laboratory experiments reported by Eastwick, Finkel, and Eagly (2010), participants, on the basis of written profiles, preferred ideal to nonideal romantic partners. After a live interaction, however, this preference disappeared, because interaction facilitated more holistic, contextual interpretation of trait information, as traditional models of person perception have long assumed (Asch, 1946). Thus, we believe that the present experiments represent a more ecologically valid test of the familiarity-attraction hypothesis than prior experiments. Building on traditional familiarity-attraction research and notwithstanding Norton et al.'s novel contribution to that literature, we propose that in the context of actual social interactions, familiarity is associated with increasing attraction. This article reports two experiments supporting this position.

\section{Explaining Why Familiarity Breeds Liking}

Familiarity effects are often couched in terms of the mere exposure effect, so we begin with a brief review of that literature. Researchers have studied diverse phenomena relevant to the mere exposure effect since it was first postulated (Zajonc, 1968). Bornstein's (1989) meta-analysis documents significant mere exposure effects with regard to several types of stimuli: sounds, ideographs, nonsense words and symbols, drawings, photographs, words and names, polygons, objects, and persons. Several of these studies were concerned with interpersonal relations. The classic study in this area is Moreland and Beach (1992). In that research, four female confederates entered a classroom in a manner visible to other students either zero, five, 10, or 15 times over the course of a semester; they did not interact with the students in the class. Afterwards, students were asked to rate the confederate on various dimensions. The more often she had been seen by students, the more she was liked and rated positively on various dimensions. Other studies have shown that the more frequently another person has been seen, the more participants rated that person positively and wanted to interact with him or her (Brockner \& Swap, 1976); the longer participants were exposed to another person's ideas, the more they liked that person (Brickman, Meyer, \& Fredd, 1975); the more familiar a negotiation partner, the more willing people are to reach compromise solutions (Druckman \& Broome, 1991); and the more familiar a public figure's picture or name, the more likeable that person is perceived to be (Harrison, 1969). In a particularly clever study, Mita, Dermer, and Knight (1977) showed that people preferred their own facial image when reversed over true facial images (because the reversed image is more familiar due to everyday grooming). Familiarity effects on liking have been observed in both Western and Asian cultures (Heine \& Renshaw, 2002), and at least one researcher has suggested that familiarity provides a necessary context for imitation in babies, an important component of cognitive development (Parker-Rees, 2007).

Familiarity effects are important in their own right and also because they have been used to explain why proximity (also called propinquity), another venerable factor in the attraction literature, predicts attraction. Many studies have shown that proximity predicts liking (e.g., Back, Schmukle, \& Egloff, 2008; Festinger, Schachter, \& Back, 1950; Nahemow \& Lawton, 1975; Segal, 1974). People tend to encounter others in close proximity more often; hence, they become more familiar.

Four general explanations have been offered for why familiarity predicts attraction. The first involves classical conditioning. Because most social experience is mildly positive in affective tone, or at least not aversive (L. A. Clark \& Watson, 1988; Denrell, 2005; Reis \& Gable, 2003), more frequently encountered others become paired with positive affect. Second, for evolutionary reasons, novel stimuli foster uncertainty and wary reactions (Lee, 2001; Orive \& Gerard, 1987), which tend to diminish once repeated exposure has shown the novel stimulus to be benign. The wary response to strangers is common in human and other animals (Rajecki, 1985). Third, familiar stimuli tend to be processed perceptually and cognitively in a more fluent manner, and fluency tends to be experienced in relatively positive affective ways (Bornstein \& D’Agostino, 1994; Winkielman, Schwarz, Fazendiero, \& Reber, 2003).

The fourth explanation, which extends the classical conditioning argument, is more directly germane to the present research. Familiarity, or repeated exposure, creates opportunities for interaction. All other things being equal, as mentioned above, positively toned interactions are more common than aversive interactions, suggesting that such opportunities are more likely than not to lead to rewarding social experiences and favorable impressions (Denrell, 2005). Because the "rewards others provide" are a central motivating factor underlying social interaction (Berscheid \& Walster, 1969) and liking (Berg, 1984), greater familiarity implies that rewarding interactions have taken place in the past. In other words, more often than not, interaction tends to be experienced on the positive side of hedonic neutrality, creating the desire for further interaction. Many social processes contribute to this tendency-for example, politeness norms, the tendency to identify common interests, and basic affiliative drives (e.g., Baumeister \& Leary, 1995).

There are some circumstances in which familiarity does not breed liking but instead breeds contempt. For example, Ebbesen et al. (1976) showed that greater familiarity with obnoxious others led to greater dislike for them, consistent with findings that repeated exposure to unpleasant stimuli does not enhance liking (e.g., Perlman \& Oskamp, 1971). If familiarity creates opportunities for interaction, then to the extent that those interactions are 
aversive, familiarity should have negative impact. This is consistent with response facilitation models of social experience: that repeated contact increases the likelihood of the dominant (i.e., most predisposed) response (Zajonc, 1965). This explanation is also consistent with research on the contact hypothesis. Although it was first assumed that intergroup contact of any sort would reduce prejudice and outgroup stereotyping, years of research have shown such contacts can make matters worse if the conditions of such contact exacerbate preexisting dislike and suspicion (Amir, 1976). On the other hand, intergroup contact under circumstances that foster cooperative interaction tends to lessen prejudice, consistent with our reasoning. In fact, conditions amenable to fostering intimate friendship appear to be especially effective in lessening prejudice and discrimination (Pettigrew, 1998).

\section{Might Familiarity Impair Liking? Norton et al.'s (2007) Research}

As mentioned above, Norton et al. (2007) argued that "less is more"- that is, that as more information about another person is acquired, the likelihood of finding evidence of dissimilarity increases, which will engender decreased liking. As they concluded in their article, "knowing more means liking less" (Norton et al., 2007, p. 103). This account follows from their finding that people anticipate initial interactions with relatively favorable expectations, because ambiguity allows for self-serving inferences about the other's opinions and traits. Three experiments (one conducted in an online dating website, the other two conducted around the Massachusetts Institute of Technology campus, omitting mention of dating or the target's sex) reported in their article relied on a similar method. Participants were presented varying amounts of trait information about a potential interaction partner; for example, in one study, participants received a list of four, six, eight, or 10 positive and negative traits randomly selected from Asch's (1946) seminal study of central and peripheral traits in impression formation. As predicted by Norton et al.'s theorizing, the more traits participants received, the less they anticipated liking the target person. In one additional study, one group of participants in an online dating service described their expectations about a forthcoming date as well as how much they knew in advance about the date. A second group was asked the same questions after a first date (with appropriate changes in tense). As expected, knowledge ratings were higher in the post-date condition, but ratings of liking and perceived similarity were lower. ${ }^{1}$

We accept these findings, and their accompanying theorizing, as far as they go. However, for the reasons spelled out next, we believe that they may misrepresent the impact of familiarity effects in actual social interactions. Several lines of reasoning lead us to this belief. First, the only one of their studies that involved interaction with another person involved online dating, which may be a special case that cannot be generalized to other forms of attraction and interaction. Online dating emphasizes evaluation, because participants typically choose among many alternative partners on the basis of information-laden profiles provided on the website (Sprecher, Schwartz, Harvey, \& Hatfield, 2008). Furthermore, dating emphasizes the sexual component of attraction in a way that ordinary social interaction does not. Berscheid and Regan (2005) explained that familiarity tends to diminish sexual attraction (opposite to its effect on nonsexual attraction), perhaps because high- arousal emotions, such as sexual arousal, depend to some extent on novelty (e.g., Berscheid \& Ammazzalorso, 2001; Reis \& Aron, 2008). For example, Wolf (1995) found that sexual attraction tends to be lower in humans raised together, an instance of the Westermarck hypothesis, which is thought to reflect evolutionary pressures related to incest taboos. Also, ever since the first computer dating study (Walster, Aronson, Abrahams, \& Rottman, 1966), researchers have recognized that impression formation in first dates is dominated by physical attractiveness in a way that may not apply to other kinds of acquaintanceships.

Second, and more importantly, lists of abstract traits, as used in trait evaluation paradigms, present information in a very structured yet decontextualized manner, which seems unlike the way in which people learn about others in everyday social interaction. For one thing, people in real conversations do not reveal information randomly. Rather, they disclose information that fits with the ebb-and-flow of the conversations, as well as with their goals (e.g., self-presentation) for that conversation (Miller \& Read, 1987). For a second reason, trait information usually comes wrapped around anecdotes and explanations, which make varying interpretations likely. For example, it seems meaningfully different to learn that a partner is "introverted" than to learn that "I felt hesitant when I went to my first campus party." Contextualization of information about others-accomplished, for example, by including individuating information about a person along with traits-can alter person perception, as has been shown in studies of social interaction with new acquaintances (Eastwick et al., 2010) or stereotyping (Smith et al., 2006). Furthermore, there are qualitative differences between live interaction and meeting someone "on paper." Notably, live interaction affords more holistic processing of information about the other (Eastwick et al., 2010), whereas trait lists would favor more analytic processing of trait information. This difference helps explain why preferences expressed in response to real interaction with potential partners in a speed-dating context may diverge from self-reports of ideal partner preferences (Eastwick \& Finkel, 2008).

Third, in conversation, people usually seek out commonalitiesother persons that both parties know, common interests, and similar experiences both have had (H. H. Clark, 1996; Stasser, Taylor, \& Hanna, 1989). This allows conversants to pursue common ground, a key component of socially shared cognition (e.g., H. H. Clark \& Brennan, 1991; Hardin \& Higgins, 1996). Thus, familiarity often leads to the perception of increased similarity (e.g., Moreland \& Zajonc, 1982).

Furthermore, familiarity in everyday social experience involves more than the acquisition of information. Another source of knowledge involves responsiveness-how partners respond to each other. Positive responses-for example, support, encouragement, humor, and engagement — tend to generate affinity, whereas uninterested or critical responses tend to foster indifference or

\footnotetext{
${ }^{1}$ One important methodological limitation of Norton et al.'s (2007) Study 5 is that all participants were recruited from an online dating website, so everyone who provided post-date ratings had gone on a date but then returned to the dating website without an explicit invitation by researchers to do so. Presumably, this means that the date had not gone well, because if the date had gone well, there would be less motivation to return to the dating website to look for a new date.
} 
animosity (e.g., Curtis \& Miller, 1986). Moreover, extensive research shows that responsiveness encourages mutual selfdisclosure (see Reis \& Patrick, 1996, for a review), creating interactions that let partners know and feel known by each other (Reis, Clark, \& Holmes, 2004). This point is consistent with research on processes such as self-verification (Swann, 1990), intimacy (Reis \& Shaver, 1988), and responsiveness goals (Canevello \& Crocker, 2010). These and many other studies suggest that perceived understanding by others contributes to feeling accepted, valued, and liked-factors that contribute to reciprocity of liking (Kenny, 1994; Newcomb, 1961). Thus, social interaction (at least when it goes reasonably well) allows for the interchange of self-disclosure and responsiveness that fosters both knowledge of the other and the feeling of being known by the other.

Finally, and more generally, familiarity fosters feeling comfortable and safe with others, which also contributes to liking (Baumeister \& Leary, 1995; Floyd, 2006; Winkielman et al., 2003). Attachment figures, for example, are almost without exception familiar, well-liked others (Mikulincer \& Shaver, 2007).

Combining these various considerations points to an important conceptual distinction. Kruglanski et al. (2000) have distinguished assessment mindsets, which emphasize analytical reasoning in which the target is evaluated relative to alternatives, from locomotion mindsets, which emphasize the commitment of selfregulatory resources to the initiation and maintenance of desired actions. Under locomotion, individuals are more likely to respond to the other spontaneously, in a manner that facilitates smooth, rewarding social interaction. Consistent with this reasoning, $\mathrm{Ku}-$ mashiro, Rusbult, Finkenauer, and Stocker (2007) demonstrated that locomotion orientations were associated with greater support, affirmation, and relationship well-being, whereas assessment orientations undermined these qualities. Extensive research based on a closely related conceptual distinction, differentiating deliberative and implemental mindsets (for reviews, see Bargh, Gollwitzer, \& Oettingen, 2010; Gollwitzer \& Bayer, 1999), similarly suggests that the former may stress purely diagnostic reasoning about the other, whereas the latter may energize efforts to achieve more harmonious, enjoyable interactions.

We reasoned that Norton et al.'s (2007) trait evaluation paradigm seems likely to have induced an assessment mindset, in which the individual asks, "Am I interested in this person?" Because they received only a list of trait adjectives, participants could only answer the researchers' question by considering the relative merits of those traits. Locomotion goals would be irrelevant, because no interaction (and hence no relationship) was possible between the evaluator and the target of the evaluation. On the other hand, actual social interactions are more likely to induce a locomotion mindset, in which the individual aims to interact in as comfortable and rewarding a manner as possible. Engaging in social interaction requires committing attention and other psychological resources to the pursuit of a smooth, non-awkward, and pleasant social experience. At the same time, this orientation would downplay critical assessments, which would interfere with spontaneity and social engagement.

This reasoning is supported by the results of an experiment by Snyder and Haugen (1995), who compared the knowledge functions (acquiring stable impressions of the other) and adjustive functions (engaging in a smooth, pleasant interaction) of gettingacquainted conversations. Importantly, they found that when no instructions were provided in such conversations, adjustive functions predominated over knowledge functions. Our reasoning is also consistent with a recent report by Frost, Chance, Norton, and Ariely (2008), who demonstrated that an online dating service that allowed potential daters "to acquire experiential information by exploring a virtual environment in interactions analogous to real first dates (such as going to a museum)" (p. 51) produced greater liking than online dating sites that emphasized what they called searchable attributes (commodities and attributes that can be described succinctly). Thus, both sets of findings support the conceptual implications of the distinction between trait evaluation and live interaction paradigms that we are proposing.

For these reasons, we expected that in the context of actual social interactions, familiarity would lead to increased liking, as earlier studies have suggested. Additionally, we expected that familiarity would increase participants' knowledge about each other (as shown by Norton et al., 2007) as well as the perception of being known by the other, and that these knowledge increases would be associated with greater liking, as the theories reviewed above suggest, rather than with decreased liking, as Norton et al. (2007) found.

\section{The Present Research}

This article reports two experiments using the live interaction paradigm testing the hypothesis that greater familiarity would predict greater attraction. In the first experiment, in face-to-face conversations, pairs of previously unacquainted participants discussed either two or six items taken from validated experimental tasks for generating closeness between strangers. These items have been demonstrated to allow conversations to unfold in a way that encourages mutual self-disclosure and supportive responses. In the second experiment, same-sex strangers were paired and randomly assigned to engage in online chats with each other one, two, four, six, or eight times. Taken as a set, these two experiments control for factors that may be associated with familiarity in real-world interactions-Study 1 controls for the topic of conversation, whereas Study 2 controls for various cues that are visible when people interact face-to-face. In addition to examining the effect of familiarity on attraction, we also examined the mediating role of two knowledge-related variables (how much knowledge participants felt that they had about their partners and how much knowledge participants felt that their partners had about them), perceived responsiveness, and comfort/satisfaction.

Both experiments were conducted with same-sex pairs because, as mentioned above, interactions between previously unacquainted opposite-sex strangers are often dominated by concerns about dating and sexual attraction. ${ }^{2}$ We were interested in studying the effects of familiarity on more general processes of attraction and friendship formation.

\footnotetext{
${ }^{2}$ Two of Norton et al.'s (2007) studies were run in a dating context and presumably involved opposite-sex pairs. The other two studies were not conducted in a dating context, and the sex-pairing is not mentioned in their article.
} 


\section{Study 1}

\section{Method}

Participants. We recruited 56 participants for the current study. Because we were primarily interested in studying initial interactions, only participants who reported (on a questionnaire at the end of the study) that they had not previously met their interaction partner were retained for analyses. Two participants who reported not knowing their partner were retained for analyses even though their interaction partners did not indicate likewise; thus, the final $N$ was 48 participants (25 women) comprising 25 different same-sex dyads. Four participants completed the study for course credit, whereas the remaining participants were recruited using flyers posted around campus and were paid $\$ 6$. Participants' mean age was 19.31 years $(S D=1.09)$, ranging from 18 to 22 years.

Measures. Attraction toward the partner was the average of four items $(\alpha=.79)$ : perceived similarity (assessed on a 7-point scale, anchored by not at all and extremely), liking for the partner and desire to have the partner as a friend (assessed on 7-point scales, anchored by neutral and an exceptional amount), and the Inclusion of Other in the Self (IOS; Aron, Aron, \& Smollan, 1992) measure. The IOS measure was translated to a 7-point scale, with higher numbers denoting greater inclusion in the self.

Perceived responsiveness was based on a scale developed by Reis (2006) but was modified to reflect new acquaintance. The 12 items are listed in the Appendix. Scores represented the average of all items $(\alpha=.93)$, all of which were assessed with 7-point scales ranging from not at all true to completely true.

Procedure. Two same-sex participants arrived at the laboratory for each experimental session. After obtaining consent, experimenters brought the two participants to an interaction room, motioned for them to sit across a table from each other, and explained that they would be having a short conversation. The experimenter then held up a set of either two or six cards, each containing a question that the participants were to ask and answer for each other. One participant ("Partner A") would ask the question, then the other participant ("Partner B") would answer for $30 \mathrm{~s}$ (using a clock on the wall to keep time). Then, Partner B would ask the same question of Partner A, and Partner A would respond for $30 \mathrm{~s}$. This process continued until all questions had been asked and answered by both participants.

Participants were randomly assigned to the two- or six-card condition. The questions on five of the cards were taken from the Relationship Closeness Induction Task (Sedikides, Campbell, Reeder, \& Elliot, 1999): "What are your hobbies?"; "What would you like to do after graduating from Northwestern?"; "What is something you have always wanted to do but probably never will be able to do?"; "If you could change anything that happened to you in high school, what would that be?"; and "What is one thing about yourself that most people would consider surprising?" The question on the other card came from Aron, Melinat, Aron, Vallone, and Bator's (1997) experimental task for generating closeness between strangers: "If a crystal ball could tell you the truth about yourself, your life, your future, or anything else, what would you want to know?" Participants in the six-card condition responded to all six questions (which the experimenter shuffled before handing to Partner A), whereas participants in the two-card condition responded to two questions randomly selected from the set of six.

The experimenter was not present in the room during the interaction. Immediately after the final questions had been answered by both participants, the experimenter reentered the room, took the participants to separate rooms, and administered a questionnaire containing the attraction and perceived responsiveness measures. Finally, participants were debriefed and dismissed.

\section{Results}

Because individual responses were nested within dyads, producing interdependence, the primary unit of analysis was the dyad (Kenny, Kashy, \& Cook, 2006). Partners' responses were correlated, $r(23)=.22, n s$, for the attraction measure, and $r(23)=.49$, $p<.02$, for the perceived responsiveness measure. We therefore used the average of both partners' responses for the primary analyses, except in the two dyads where measures were retained for only one of the two partners (see the Method section). In these two dyads, we used the ratings from the participant who reported not knowing the other participant in advance. ${ }^{3}$

Preliminary analyses found no main effects or interactions involving the dyad's sex, $F \mathrm{~s}(1,21)<1.95, n s$, so we did not include sex in the primary hypothesis tests. Consistent with experimental instructions, in the two-card condition, participants conversed for $129 \mathrm{~s}$, on average; in the six-card condition, their conversations averaged $394 \mathrm{~s}, t(13)=10.93, p<.001$.

Analysis of the attraction composite yielded a significant mean difference, $t(23)=2.23, p<.04, d=0.91$. In the two-card condition, the mean level of attraction was $3.55(S D=0.75)$; in the six-card condition, the mean level of attraction was $4.17(S D=$ 0.61 ). Thus, additional conversation led to increased attraction, as we predicted.

Additional interaction led to marginally higher ratings of perceived responsiveness, as expected, $t(23)=1.83, p<.09, d=$ 0.75. In the two-card condition, the mean level of perceived responsiveness was $2.74(S D=0.80)$; in the six-card condition, it was $3.27(S D=0.62)$.

\section{Brief Discussion and Introduction to Study 2}

Study 1 demonstrated that when same-sex strangers had a chance to become more familiar with each other, their attraction increased. Thus, the study supports our hypothesis that when familiarity is augmented in the context of social interaction, it has a beneficial effect on attraction. Because Study 1 used an experimental design that controlled the topics of conversation, it provides firmer evidence than earlier studies do that familiarity may enhance attraction in social interaction. Of course, sitting in a laboratory room discussing topics chosen by an experimenter for $30 \mathrm{~s}$ each is not an entirely "natural" social interaction. Informational flow is restricted, participants experience little choice about their participation or what they are saying, and the laboratory context invites speculation about the true purposes of the experiment. Ickes (2009) has described the often-substantial impact that such con-

\footnotetext{
${ }^{3}$ If data from both of the omitted participants are used, the pattern of results remains the same.
} 
textual factors may have on spontaneous social interaction. Therefore, in Study 2, we sought to create a more natural and engaging context for testing our hypothesis. We did this by randomly assigning strangers to chat online for a varying number of instances. There were no restrictions on the content of their chats or timing of their chats (save that we asked that the chats last about $15 \mathrm{~min}$ each and occur within the same numbers of days in their assigned number-of-chats condition). Additionally, participants could access the instant messaging program from any location. Once again, we hypothesized that greater numbers of chats would be associated with greater attraction. We also hypothesized that this association would be mediated by perceived knowledge, responsiveness, and comfort/satisfaction, as described earlier.

\section{Study 2}

\section{Method}

Participants. We recruited 242 participants (178 women) from the University of Rochester Psychology participant pool in exchange for course extra credit. Their mean age was 19.46 years $(S D=1.23)$, ranging from 18 to 24 years. Eight dyads never made contact with each other and were not considered. Three additional dyads, one each in the two-chat, six-chat, and eight-chat conditions, were dropped because of completing fewer than $50 \%$ of the required numbers of chats. ${ }^{4}$ Thus, study analyses were based on 110 dyads. To encourage timely compliance with our procedures, participants received a lottery ticket for one of six cash prizes, three for $\$ 50$ and three for $\$ 25$, according to the following schedule: Having the first conversation within $24 \mathrm{hr}=$ two lottery tickets; having no more than one conversation each day $=$ five lottery tickets; completing all conversations = five lottery tickets (regardless of condition); completing the follow up surveys on time $=$ four lottery tickets. Thus, participants could earn up to 16 lottery tickets, and this was unrelated to their condition or the number of chats.

\section{Measures.}

Pre-chat measures. Students were asked to describe how much they like and feel similar to the "average" student at the University of Rochester. These ratings were made using 7-point Likert-type scales ranging from 1 (not at all) to 7 (extremely).

Post-chat measures. After their final chat, participants were e-mailed a link to an online survey. On average, post-chat data were obtained 1.18 days after the final chat $(S D=1.86$; range $=$ 0-12 days). Participants were asked to provide several ratings of their partner and interactions. As in Study 1, four items contributed to a composite measure of attraction toward the partner: perceived similarity (assessed on 7-point scales, anchored by not at all and extremely), liking for the partner and desire to have the partner as a friend (assessed on 7-point scales, anchored by neutral [or dislike] and an exceptional amount), and perceived closeness (the IOS measure; Aron et al., 1992). Values were translated to a 7-point scale, with higher numbers denoting greater closeness. As in Study 1, these four items were combined into a composite measure of attraction $(\alpha=.87)$.

Additional items assessed perceived responsiveness (12 items, based on the measure developed by Reis, 2006, assessed with 7-point scales ranging from not at all true to completely true; $\alpha=$ $.95)$; perceived knowledge about their partner's interests, family, school, and social life (four items taken from Norton et al., 2007, assessed with 7-point scales ranging from nothing at all to an exceptional amount; $\alpha=.72$ ); their perception of their partner's knowledge about them (identical items and scales; $\alpha=.74$ ); and satisfaction, enjoyment, and comfort with the interactions (five items, assessed with 5-point scales ranging from not at all to extremely; $\alpha=.90)$. Participants were also asked whether they wanted to contact their partner after the study was over. We provided contact information to partners who mutually indicated interest in contact.

Two-week follow-up. Two weeks after their final conversation, participants were sent an e-mail asking them to indicate whether they had attempted to contact their partner. Two hundred and six participants (94\%) responded to this question. Two dyads did not respond to the 2-week follow-up e-mail, and 98 dyads included data from both partners. Ten dyads included data from only one partner, and this response was used in the analyses.

Coding of conversations. All transcripts were coded in random order by three independent coders who were unaware of condition, the hypotheses of the study, or the identity of the conversants. In all, five coders were used. One coder rated all transcripts, whereas the other four coders each rated approximately half of the transcripts, randomly assigned. There were a few differences between coders in their mean ratings and variance. These differences were corrected by adjusting all scores so that each coder had the same mean and standard deviation for each dimension coded. Coders rated each transcript on five dimensions relevant to this study, using 7-point scales: knowledge and familiarity about each other ("To what degree does the individual seem to know the other person's traits, facts about their life, etc."), references to prior conversations ("How many times did partners refer to things they talked about in previous conversations?"), perceived liking ("Based on the conversation as a whole, how much do you think the participant likes their partner?"), selfdisclosure of personal information ("To what extent did the individual reveal relatively private information and emotions?"), and degree of emotional expression ("To what extent did the participant explicitly say that they feel or were feeling a particular emotion?"). Correlations between each pair of two coders for the five coded variables ranged from .45 to .64 , with a mean $r=.54$. Scores were created by summing the adjusted scores of all three coders for each transcript.

We then reduced these five codes to three variables by creating composite scores for expressed knowledge-the mean of knowledge and references, $r(106)=.77, p<.001$-and selfrevelation-the mean of self-disclosure and emotional expression, $r(106)=.38, p<.001$. The perceived liking code was used on its own.

Finally, we computed the total number of words in each chat transcript using the Linguistic Inquiry and Word Count program (Pennebaker, Francis, \& Booth, 2001).

Procedure.

Pre-chat briefing. After obtaining consent, experimenters provided instructions to participants one at a time. Participants were told that they would be paired with another student from the university who was not affiliated with the study, whom they did

\footnotetext{
${ }^{4}$ Findings remain unchanged if these dyads are included.
} 
not know, and who was same sex. To minimize the chance that participants knew their partner, we recorded their dormitory and, where applicable, sports teams, Greek organization, and other extracurricular activities that occupied at least $5 \mathrm{hr}$ per week. Individuals were randomly assigned to conditions, using a random numbers table, and then were matched with the last unpaired person, with the constraint that individuals who matched on any of the aforementioned criteria were not partnered. We then provided full instructions for the study.

Participants were given an anonymous screen name and password with which to log into the instant messaging client (e.g., urpsych1). They were asked to chat for approximately 10-15 min with their partner for a pre-specified number of times, depending on condition (one, two, four, six, or eight times), once a day if possible but spanning no more than the number of days in the assigned condition (e.g., 8 days for the eight-chat condition). We requested that participants not interact more than twice a day, but if they did so, to space their interactions by at least $2 \mathrm{hr}$. We provided no guidelines on how to structure interactions, except to request that each participant contribute to each conversation at least six times (to keep it from becoming one-sided). Participants were free to talk about whatever topics naturally arose during the course of their conversation. We encouraged participants to maintain anonymity as follows:

In all likelihood you won't know this person, and in fact, our preference, for your safety and for the integrity of the study, is that you don't reveal your true identity while online with your partner. Identities may come up if you choose, but our preference is for you to remain anonymous. You will have an opportunity at the end of the study to reveal your identity to the other person.

The chats were not pre-scheduled but were instead left to occur naturally. The first interaction was often the most difficult to arrange, as it required both participants to be online at the same time, using the screen names we provided rather than their own. We used AOL-Instant Messenger, which allows individuals to post times that they plan to be available to chat as an "away message." If a pair failed to connect within $24 \mathrm{hr}$, an experimenter intervened by e-mailing participants individually and manually coordinating the first interaction. This occurred for eight dyads.

After receiving instructions, participants provided the pre-chat measures as well as a series of self-report trait measures not relevant to the current research.

Compliance procedure. Every day, an experimenter sent separate e-mails to all active participants, reminding them to chat with their partner and informing them about how many conversations had been completed and how many remained. Included in daily e-mails was a link for participants to follow to submit their conversations. Participants were instructed to follow the link after every conversation and to submit a transcript of their conversation to our online survey website.

\section{Results}

Because individual responses were nested within dyads, producing interdependence, the primary unit of analysis was the dyad (Kenny et al., 2006), as in Study 1. Except where otherwise noted, all variables were the average of both partners' responses. Data were analyzed with planned contrasts, in which the primary hy- pothesis specified a linear trend across the five conditionsnamely, that attraction (or other relevant variables) would increase as a function of condition. A linear trend contrast uses 1 degree of freedom $(d f)$. Rosenthal, Rosnow, and Rubin (2000) recommended that when a study has multiple degrees of freedom but the primary hypothesis uses only $1 d f$, one should test for significant effects in the remaining between-groups variance with $F$-noncontrast, which in this case has $3 d f$ s (five groups have $4 d f$ s minus 1 for the hypothesized linear contrast). This analysis identifies whether significant nonlinear effects were present.

Preliminary analyses were conducted to examine whether the linear or $F$-noncontrast effects on key study variables interacted with dyad sex. No significant effects were found. Consequently, sex was not incorporated into the analyses reported below. We also examined pre-chat ratings of how much participants liked and felt similar to the average University of Rochester student, to ensure that there were no pre-existing differences across conditions. For each question, the linear contrast was nonsignificant, $F \mathrm{~s}(1,102) \leq$ $1.01, n s$, as was the noncontrast effect, $F \mathrm{~s}(3,102) \leq 1.30$, ns.

Compliance. Compliance with our complex protocol was strong. In the one-chat condition, 18 dyads completed one chat. In the two-chat condition, 18 dyads completed two chats, and two dyads completed one chat. In the four-chat condition, 21 dyads completed all four chats, one dyad completed five chats, one dyad completed three chats, and two dyads completed two chats. In the six-chat condition, 25 dyads completed all six chats, four completed seven chats, one completed five chats, and one completed four chats. In the eight-chat condition, 10 dyads completed all eight chats, one dyad completed nine chats, three completed seven chats, and two completed six chats. Thus, for the analytic sample, 92 out of 110 dyads $(84 \%)$ completed the required number of chats, and 105 out of $110(95 \%)$ came within one of the required number.

Hypothesis tests. Our main hypothesis was that there would be a linear increasing trend for attraction across the five conditions. This hypothesis was tested by examining ratings from the postchat measure. Attraction produced a significant linear trend across conditions, $F(1,101)=5.15, p<.03$. Figure 1 displays the relevant condition means. The residual between-conditions variance was not significant, $F$-noncontrast $(3,101)=0.98, n s$.

The perceived knowledge and responsiveness measures also yielded significant linear contrasts (see Table 1 for the relevant descriptive statistics). For perceived knowledge of the partner, the linear trend was significant, $F(1,99)=43.85, p<.001$, as was the

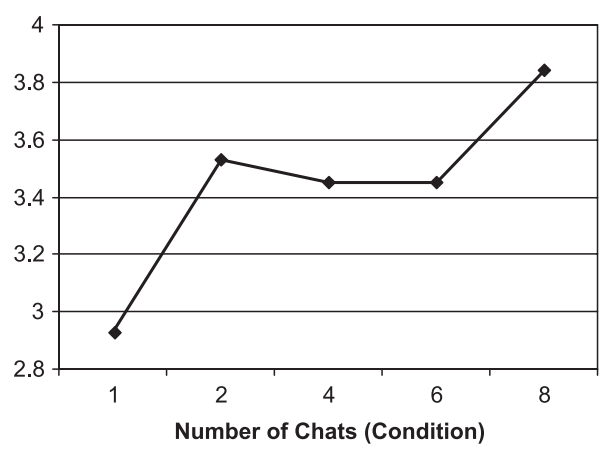

Figure 1. Attraction as a function of the number of chats (condition). 
Table 1

Levels of Perceived Knowledge and Responsiveness as a Function of the Number of Chats

\begin{tabular}{|c|c|c|c|c|c|c|c|}
\hline \multirow[b]{2}{*}{ Measure } & \multicolumn{5}{|c|}{ Condition (number of chats) } & \multirow[b]{2}{*}{ Linear $F$} & \multirow[b]{2}{*}{$F$-noncontrast } \\
\hline & 1 & 2 & 4 & 6 & 8 & & \\
\hline Perceived knowledge of other & $1.99(0.56)$ & $2.92(0.56)$ & $3.11(0.64)$ & $3.16(0.62)$ & $3.52(0.86)$ & $43.85^{\text {****** }}$ & $3.42^{* *}$ \\
\hline Perceived knowledge by other & $1.92(0.54)$ & $2.79(0.51)$ & $2.97(0.78)$ & $3.08(0.69)$ & $3.30(0.75)$ & $36.19^{* * * * *}$ & $2.76^{*}$ \\
\hline Perceived responsiveness & $2.40(0.72)$ & $3.09(0.76)$ & $3.12(0.80)$ & $3.44(1.08)$ & $3.29(0.91)$ & $11.30^{* * * * *}$ & 1.42 \\
\hline Satisfaction/comfort & $3.11(0.78)$ & $3.62(0.40)$ & $3.58(0.63)$ & $3.66(0.70)$ & $3.77(0.71)$ & $7.32^{* * * *}$ & 1.05 \\
\hline
\end{tabular}

Note. Mean levels are presented; standard deviations are reported in parentheses.

${ }^{*} p<.05 .{ }^{* *} p<.02$ **** $^{*} p<.01$ **** $^{*} p<.001$.

noncontrast test, $F(3,99)=3.42, p<.03$. Post hoc analyses indicated that this result stemmed from the larger increase from one-chat to two-chat relative to the other condition differences. Perceived knowledge of the self also produced a significant linear trend across conditions, $F(1,99)=36.19, p<.001$, and a significant effect for the remaining variance, $F$-noncontrast(3, $99)=2.76, p<.05$. Post hoc tests again revealed that this was due to a larger increase from one-chat to two-chat relative to the other condition.

Perceived responsiveness yielded similar results: a significant linear trend across conditions, $F(1,101)=11.30, p<$ .001 , and a nonsignificant effect for the remaining variance, $F$-noncontrast $(3,101)=1.42, n s$. As Table 1 shows, all three variables showed increases as the number of chats increased. We also analyzed how satisfied and comfortable participants felt during their chats. As shown in Table 1, the linear trend was significant, $F(1,101)=7.32, p<.01$, whereas the residual between-groups variance was not, $F$-noncontrast $(3,101)=$ $1.05, n s$.

After the chats had been completed, we gave participants the opportunity to learn each other's identity, so that they might continue their interactions. This was done in part to provide a more externally valid measure of attraction. Two measures were obtained. The first examined the percentage of dyads in which at least one participant expressed the desire to learn the other's identity to get in contact. This was done with a one-tailed linear chi-square test, using Fisher's exact probability, and was significant, $\chi^{2}(1)=6.18, p<.01$. The percentages of dyads in which at least one person expressed a desire for further contact were $17.6 \%, 41.2 \%, 52.4 \%, 51.6 \%$, and $62.5 \%$, in the one-, two-, four-, six-, and eight-chat conditions, respectively. The second test, based on a question asked 2 weeks after the final chat, looked at the percentage of dyads in which at least one participant reported actually trying to contact the other. Because some participants exchanged names or other identifying information during their conversations, we included all participants in this analysis rather than restricting it to those for whom we had facilitated an exchange of contact information. A similar one-tailed linear chi-square test, using Fisher's exact probability, was significant, $\chi^{2}(1)=2.83, p=.05$. The percentages of dyads in which at least one person actually attempted contacting the other were $11.1 \%, 15.0 \%, 25.0 \%$, $26.7 \%$, and $31.3 \%$, in the one-, two-, four-, six-, and eight-chat conditions, respectively.

Thus, participants in the eight-chat condition were almost four times more likely than participants in the single-chat condition to desire further contact after their scheduled chats, and they were almost three times more likely to actually try to contact their partner within 2 weeks.

Coding of transcripts. To determine whether participants' perceptions of their interactions would be reflected in objective characteristics of those conversations, we analyzed independent coder ratings of the last conversation that each dyad had. Here, we examined only the final transcript for each dyad, because we wanted to determine whether the follow-up ratings (which were obtained after the final chat had occurred) reflected the state to which participants' relationships had evolved over their various chats. Results of these analyses are displayed in Table 2. For each variable, the rated value generally increased as the assigned number of chats increased. There was a strong linear trend for expressions of knowledge about each other to increase as a function of the number of chats, $F(1,104)=25.29, p<.001$. The noncontrast effect was also significant, $F(3,104)=3.56, p<.005$, reflecting

Table 2

Levels of Coded Knowledge, Liking, and Self-Revelation in Dyads' Final Chat as a Function of the Number of Chats

\begin{tabular}{|c|c|c|c|c|c|c|c|}
\hline \multirow[b]{2}{*}{ Measure } & \multicolumn{5}{|c|}{ Condition (number of chats) } & \multirow[b]{2}{*}{ Linear $F$} & \multirow[b]{2}{*}{$F$-noncontrast } \\
\hline & 1 & 2 & 4 & 6 & 8 & & \\
\hline Knowledge about each other & $-0.61(0.11)$ & $-0.09(0.59)$ & $0.42(0.69)$ & $0.50(0.82)$ & $0.31(0.83)$ & $25.29^{* * * * *}$ & $3.56^{* *}$ \\
\hline Rated liking & $-0.14(0.51)$ & $0.09(0.65)$ & $0.23(0.81)$ & $0.40(0.98)$ & $0.31(1.06)$ & $4.17^{*}$ & 0.30 \\
\hline Self-revelation & $-0.10(0.34)$ & $-0.04(0.39)$ & $0.12(0.71)$ & $0.18(0.55)$ & $0.33(0.88)$ & $5.83^{* * *}$ & 0.06 \\
\hline Word count & $530.7(159.1)$ & $527.2(246.6)$ & $490.5(142.5)$ & $528.9(233.0)$ & $523.8(239.2)$ & 0.00 & 0.21 \\
\hline
\end{tabular}

Note. Mean levels are listed; standard deviations are reported in parentheses.

${ }^{*} p<.05$. ** $p<.02$. ***** $p<.001$. 
an apparent drop-off in the eight-chat condition. ${ }^{5}$ Ratings of perceived liking also yielded a significant linear trend, $F(1,104)=$ $4.17, p<.05$, and a nonsignificant noncontrast effect, $F(3,104)=$ $0.30, n s$. Likewise, self-revelation yielded a significant linear trend, $F(1,104)=5.83, p<.02$, and a nonsignificant noncontrast effect, $F(3,104)=0.06, n s$.

As shown in Table 2, there were no meaningful differences across conditions in number of words used in these conversations, $F(1,104)=0.00, n s$.

Mediation analyses. To examine mediation of the effect of familiarity on attraction, we adopted a bootstrapping approach (Preacher \& Hayes, 2004, 2008). Bootstrapping evaluates the magnitude of an indirect effect by comparing it with the sampling distribution of multiple resamples of the data set. Importantly, because bootstrapping makes no assumptions about normality in the data distribution, it corrects for possible bias in the obtained confidence intervals, thereby improving the quality of inference in mediation models (MacKinnon, Lockwood, \& Williams, 2004). We used this method to evaluate whether perceived knowledge, perceived responsiveness, and comfort/satisfaction mediated the linear effect of familiarity on attraction. For simplicity, we combined the two knowledge variables into a single composite. Contrasts representing the residual between-groups variance were also included as control variables. A total of 5,000 resamples and 95\% confidence intervals (i.e., establishing that the indirect effects were significant at two-tailed $p<.05$ ) were used.

Because our theoretical model specified that knowledge, responsiveness, and comfort would all play a role in mediating the effects of familiarity on attraction, we first evaluated each of the three mediators individually. In each case, the indirect effect was significant, and the direct effect of the linear contrast was reduced to nonsignificance. For perceived responsiveness, the indirect effect was significant: $a b=0.167, S E=0.052,95 \%$ CI [0.071, 0.275]; direct effect $b=0.006, S E=0.050, t(100)=0.13, p<.90$. For comfort/satisfaction, the indirect effect was significant: $a b=$ $0.136, S E=0.058,95 \%$ CI $[0.030,0.262]$; direct effect $b=0.036$, $S E=0.052, t(100)=0.69, p<.49$. For perceived knowledge, the indirect effect was also significant: $a b=0.243, S E=0.056,95 \%$ CI [0.146, 0.371]; direct effect $b=-0.070, S E=0.070, t(98)=$ $-1.00, p<.33$. Thus, when considered independently, each of the three proposed mediating variables yielded a significant indirect effect.

Because the three potential mediators were highly correlatedknowledge-responsiveness, $r(104)=.64$; knowledge-comfort, $r(104)=.56$; responsiveness-comfort, $r(106)=.72$; all $p s<$ .001 - we also evaluated our mediation hypothesis by entering all three mediators simultaneously in a single model, following the same procedures as described above. Figure 2 displays results from this mediation analysis. The indirect effect for perceived responsiveness was significant $(a b=0.100, S E=0.038,95 \%$ CI [0.039, $0.189])$, as was the indirect effect for comfort/satisfaction $(a b=$ $0.063, S E=0.033,95 \%$ CI $[0.013,0.148])$. In other words, controlling for the other mediators, the linear main effect, and the residual between-groups variance, perceived responsiveness and comfort/satisfaction significantly mediated the effect of the contrast on attraction. For perceived knowledge, however, the indirect effect was not significant $(a b=0.042, S E=0.040,95 \% \mathrm{CI}$ $[-0.028,0.134])$, which seems likely due to the high covariation between the three mediators. In sum, as Figure 2 displays, when

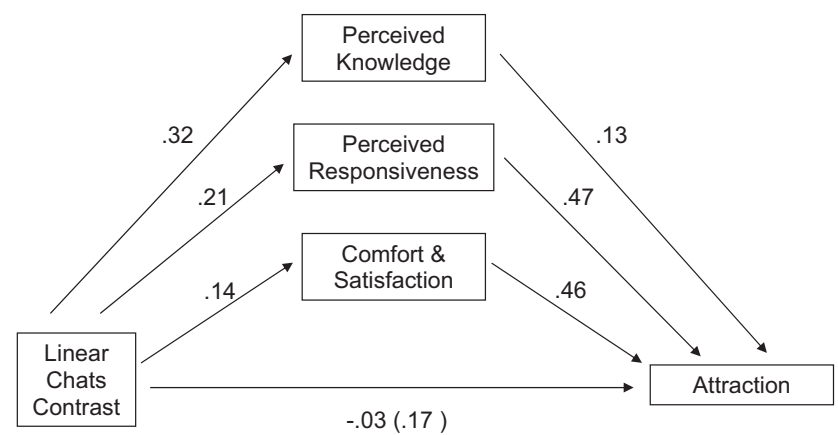

Figure 2. Proposed mediational model. All coefficients are significant at $p<.05$ or less except for the direct effect of the linear condition contrast when the three mediators are included in the model.

the three mediators are included in the model, the linear familiarity contrast becomes nonsignificant: $b=-0.032, S E=0.051, t(96)=$ $-0.63, p<.53$.

When multiple mediators are included, the Preacher and Hayes bootstrapping approach also permits comparisons of the magnitude of the indirect effects. None of these contrasts were significant, indicating that in the simultaneous analyses the three indirect effects did not differ significantly from one another in magnitude.

\section{Brief Discussion of Study 2}

As hypothesized, attraction increased between chat partners as the number of conversations increased. Several other variables thought to be relevant to the familiarity effect also increased correspondingly: perceived knowledge of the other, perceived knowledge of oneself by the other, perceived responsiveness, and satisfaction/comfort with their chats. No other trends were consistently significant across condition. Coder ratings of perceived knowledgeability, liking, and self-revelation revealed similar trends. Finally, two behavioroid measures of attraction, expressions of the desire to reveal one's identity to get in contact and reports of trying to get into contact with the other, supported findings from the self-report and coder ratings by showing increasing frequencies as a function of the number of chats. Mediation analyses generally supported our reasoning that responsiveness, comfort, and knowledge would account for the attraction effect, although the indirect effect for knowledge fell short of significance when all three mediators were included simultaneously. Thus, our hypothesis that in natural social interaction, familiarity is associated with increased attraction was supported.

\section{General Discussion}

Across two experiments using different versions of a live interaction paradigm, we found clear support for our hypothesis that increasing familiarity would be associated with greater attraction. In Study 1, same-sex strangers discussed for about $30 \mathrm{~s}$ each either two or six topics chosen to facilitate the type of conversation that promotes acquaintanceship (Aron et al., 1997; Sedikides et al.,

\footnotetext{
${ }^{5}$ Consistent with this observation, the quadratic trend was significant $F(1,104)=9.76, p<.005$.
} 
1999). Chats in Study 2 were more spontaneous and unconstrained-conditions that allow individual differences and personal preferences to emerge (Ickes, 2009). In this case, randomly paired same-sex strangers engaged in varying numbers of online chats. Both studies found increased attraction as a function of increasing amounts of interaction. Importantly, Study 2 included measures of three variables thought to be responsible for these effects: perceived knowledge, perceived responsiveness, and comfort/satisfaction. Linear condition effects for these variables corresponded to the results for attraction, in both participants' selfreports and observer's independent coding. Clear support was obtained for perceived responsiveness and comfort/satisfaction as mediators of the familiarity-attraction link; evidence also supported perceived knowledge as a mediator, although this evidence was somewhat more tentative.

The present studies are to our knowledge the first experiments of familiarity and attraction that directly manipulated the amount of social contact while allowing interactions to unfold in a natural, spontaneous way. These results directly contest Norton et al.'s (2007) conclusion that "familiarity breeds contempt" (p. 97). To be sure, we do not dispute the validity of Norton et al.'s findings, insofar as they go. That is, if familiarity is limited to the assessment of decontextualized positive and negative trait-adjective descriptors, it is plausible that familiarity breeds contempt, as their results indicate. Our position, however, is that familiarity in actual social activity is considerably more complex and personally engaging than this. As described in the introduction, in spontaneous social interaction, people typically share information in a more interactive, contextualized, and individuated manner, and they process that information more holistically (Eastwick et al., 2010). In other words, interaction partners often learn about each other in a manner that highlights common interests and promotes enjoyable conversation and favorable impressions. Importantly, in our Study 2 , both measures of perceived knowledgeability-perceptions of self-knowledge about the other and of other-knowledge about the self-were greater as a function of increased familiarity, for both participant self-reports and observer codes. Knowledge is the exact factor that Norton et al. have theorized should decrease attraction-recall their argument that information precludes the perception of similarity that ambiguity fosters-yet, in our research, both knowledge and attraction increased as a function of familiarity, as we (and prior work on the familiarity effect) have asserted.

Our finding is consistent with prior studies showing that more experience with others may increase confidence and decrease uncertainty in impressions of others (both of which seem likely to contribute to liking). For example, Swann and Gill (1997) found that relationship length in both romantic and same-sex friendship contexts was positively associated with confidence about impressions of others, an association that was mediated by the richness of these impressions (a composite of the amount, integration, and accessibility of information about the other). Similarly, Oskamp (1965) showed that clinical psychologists' confidence about personality judgments of hypothetical cases increased as a function of the amount of information they had available. Moreover, Funder and his colleagues (e.g., Funder \& Colvin, 1988; Letzring, Wells, $\&$ Funder, 2006) have shown that the quantity and diversity of information that friends and intimates have about each other (in comparison with less well-acquainted others and strangers) are associated with greater accuracy in judging personality traits, a key provision of Funder's (1995) realistic accuracy model.

Two other mediating variables contributed to our observed effects: perceived responsiveness and comfort/satisfaction. We think it likely that these factors are salient when people are focused on interacting with others. Familiarity promotes responsive interaction and, hence, attraction in several ways. First, when people become acquainted, they are better able to offer personally relevant encouragement and support (Reis et al., 2004). Also, familiarity fosters the provision of self-verifying feedback, because partners are more aware of each other's attributes and viewpoints (Swann, 1990). Finally, we propose that there is a mutually reinforcing cycle of increasing responsiveness and attraction, consistent with Canevello and Crocker's (2010) findings about responsiveness goals: The more one is attracted to the other, the more motivated one is to be responsive to him or her. Responsive behavior by one partner, in turn, fosters the other's attraction. This is reminiscent of "mutual cyclical growth," a process described by Wieselquist, Rusbult, Foster, and Agnew (1999) with regard to the development of trust. One partner's pro-relationship behavior enhances the other's satisfaction and commitment, which in turn leads that partner to engage in pro-relationship behavior that benefits the other. It is also consistent with M. S. Clark's account of partners' mutual concern for each other's well-being in communal relationships (e.g., M. S. Clark \& Mills, 2001).

As for the third mediator, comfort/satisfaction, a similar selfreinforcing cycle seems likely to be operative. Familiarity promotes feeling comfortable with a new acquaintance, and as comfort increases, so does attraction. Presumably this would occur in natural social interaction except when those interactions are aversive (Ebbesen et al., 1976). Increased attraction may then contribute to the likelihood that subsequent interactions would be experienced as comfortable and rewarding (Berg, 1984), adding to the likelihood of increased attraction (e.g., Collins \& Miller, 1994).

Conceptually, our results and those of Norton et al. (2007) may be reconciled by considering the difference between evaluating information and interacting with others, which in turn may have influenced the mindset of participants in their and our studies. As described earlier, their research emphasized assessment: Participants were given bits of information and were asked how much they might like this person. Our studies, in contrast, emphasized locomotion: Participants had to interact with peers, which would make salient the goal of engaging in a pleasant, enjoyable interaction (Snyder \& Haugen, 1995). Both orientations apply to relationship initiation and developing acquaintanceship, albeit in different contexts. Some contexts (e.g., online dating) emphasize assessment orientation, by providing information and by asking participants to evaluate the likeability of that person. Because assessment of static information often tends to be critical (Frost et al., 2008; Kumashiro et al., 2007), in these instances familiarity may provide more reasons to regard another person warily. On the other hand, spontaneous interaction usually involves goals of one sort or another (e.g., to enjoy interacting, to accomplish some task), which would foster a locomotive orientation. In this more natural context, familiarity is more likely to increase attraction, for the reasons discussed earlier and as our results demonstrate. Of course, our research did not manipulate these orientations, so we cannot say whether this proposed conceptual 
reconciliation of our results with Norton et al.'s is correct. Further research is needed.

This study adds to the existing literature on familiarity in another way. Prior studies generally used one of two formats: experimental studies in which pictures or names were shown to participants for varying frequencies, or correlational studies in which the frequency of social exposure or contact was measured and then linked to attraction. (Moreland \& Beach, 1992, is an exception, but note that that experiment involved no actual interaction between participants and confederates.) As mentioned above, the present experiments are to our knowledge the first that directly manipulated the amount of social contact in a naturalistic context. Furthermore, note that our studies controlled several other important processes that, in natural acquaintanceships, may be confounded with increasing familiarity. For example, Study 1 controlled the topic of conversations. In Study 2, participants did not meet face-to-face (and thus had no information about physical attractiveness) or learn each other's name until after the study had been completed. Thus, they had no information about appearance or popularity or what others in their social network thought about the partner. All they knew was what they had learned and experienced through interacting. In sum, our studies add empirical strength to the principle that familiarity fosters attraction.

It bears noting that although the three mediators that we examined are conceptually distinguishable, we cannot determine whether each one is necessary or sufficient to produce the effects (although the analyses conducted with individual mediators suggest that each is influential). On the other hand, in actual acquaintanceships, it seems likely that all three processes co-occur, as they did here. We think it unlikely that responsiveness would grow in a relationship without perceived knowledgeability or comfort, comfort without knowledgeability and responsiveness, and knowledgeability without responsiveness or comfort. Thus, and notwithstanding the fact that experimental scenarios might well be able to isolate the effects of these variables relative to one another, our analyses seem to mirror reasonably closely the emergence of attraction from familiarity as it occurs in real-life.

\section{Limitations}

These results should be considered in the context of several limitations. First, both studies required participants to engage in a pre-determined number of conversations to receive course credit. This effectively ruled out the possibility of terminating the relationship after a single, perhaps unrewarding conversation, as may often occur in real-life. (Of course this limitation might also be considered a strength, in showing that attraction can develop after artificially inducing repeated interactions with a stranger to whom one initially feels no attraction or perhaps even repulsion; Aron, Steele, Kashdan, \& Perez, 2006.) Second, because all participants were reasonably similar in certain respects (i.e., young adults studying at the same university, taking a psychology course), it is possible that enough pre-existing similarity existed to predispose attraction. Similarity effects on attraction are well-established, particularly with regard to relationship initiation (Montoya, Horton, \& Kirchner, 2008). In contrast, the information acquired in Norton et al.'s (2007) research fostered impressions of dissimilarity. Of course, in actual social encounters, people are more likely to come into contact with relatively similar than dissimilar others (e.g., Bandura, 1982), but it would be interesting to see whether comparable results would be obtained with a more diverse sample or when people are explicitly paired with outgroup members (e.g., an Israeli Jew with a Palestinian Muslim).

A third limitation is that we did not assess participants' actual knowledge about each other-which might have been done, for example, by comparing ratings of the other with self-ratings. Nevertheless, existing research suggests that perceived knowledgeability may be more important than actual knowledge for the development of relationships (Murray, Holmes, Bellavia, Griffin, \& Dolderman, 2002; Pollmann \& Finkenauer, 2009). In this regard, independent coders' ratings confirmed participants' selfreports of increased knowledgeability. A fourth limitation is that this research was conducted in an individualist culture, which tends to encourage outgoing behavior and the casual formation of social bonds. Several studies have suggested that friendships may develop more cautiously in collective cultures (e.g., Triandis, Bontempo, Villareal, Asai, \& Lucca, 1988), and in such cultures, it may take longer for familiarity effects to emerge.

\section{Conclusion}

These live-interaction experiments indicate that researchers may feel confident returning familiarity to the pantheon of socialpsychological processes that promote attraction. To be sure, there are boundary conditions to this effect and circumstances in which it does not hold true. It would be desirable in future research to identify these conditions, particularly contextual factors and individual differences (e.g., age, personality) that may moderate familiarity effects. However, as a general rule, in spontaneous, everyday social interactions among newly acquainted peers, familiarity does indeed tend to breed liking rather than contempt. In other words, less is, after all, less.

\section{References}

Amir, Y. (1976). The role of inter-group contact in change of prejudice and ethic relations. In P. A. Katz (Ed.), Towards the elimination of racism (pp. 245-308). New York, NY: Pergamon.

Aron, A., Aron, E. N., \& Smollan, D. (1992). Inclusion of Other in the Self Scale and the structure of interpersonal closeness. Journal of Personality and Social Psychology, 63, 596-612. doi:10.1037/0022-3514.63.4.596

Aron, A., Melinat, E., Aron, E. N., Vallone, R. D., \& Bator, R. J. (1997). The experimental generation of interpersonal closeness: A procedure and some preliminary findings. Personality and Social Psychology Bulletin, 23, 363-377. doi:10.1177/0146167297234003

Aron, A., Steele, J. L., Kashdan, T. B., \& Perez, M. (2006). When similars do not attract: Tests of a prediction from the self-expansion model. Personal Relationships, 13, 387-396. doi:10.1111/j.14756811.2006.00125.x

Asch, S. E. (1946). Forming impressions of personality. Journal of Abnormal and Social Psychology, 41, 258-290. doi:10.1037/h0055756

Back, M. D., Schmukle, S. C., \& Egloff, B. (2008). Becoming friends by chance. Psychological Science, 19, 439-440. doi:10.1111/j.14679280.2008.02106.x

Bandura, A. (1982). Psychology of chance encounters and life paths. American Psychologist, 37, 747-755. doi:10.1037/0003-066X.37.7.747

Bargh, J. A., Gollwitzer, P. M., \& Oettingen, G. (2010). Motivation. In S. Fiske, D. Gilbert, \& G. Lindzey (Eds.), Handbook of social psychology (5th ed., pp. 268-316). New York, NY: Wiley.

Baumeister, R. F., \& Leary, M. R. (1995). The need to belong: Desire for 
interpersonal attachment as a fundamental human motivation. Psychological Bulletin, 117, 497-529. doi:10.1037/0033-2909.117.3.497

Berg, J. H. (1984). Development of friendship between roommates. Journal of Personality and Social Psychology, 46, 346-356. doi:10.1037/ 0022-3514.46.2.346

Berscheid, E., \& Ammazzalorso, H. (2001). Emotional experience in close relationships. In G. J. O. Fletcher \& M. S. Clark (Eds.), Blackwell handbook of social psychology (Vol. 2, pp. 308-330). Oxford, England: Blackwell.

Berscheid, E., \& Regan, P. (2005). The psychology of interpersonal relationships. Upper Saddle River, NJ: Pearson Education.

Berscheid, E., \& Walster, E. H. (1969). Interpersonal attraction. Reading, MA: Addison Wesley.

Bornstein, R. F. (1989). Exposure and affect: Overview and meta-analysis of research, 1968-1987. Psychological Bulletin, 106, 265-289. doi: 10.1037/0033-2909.106.2.265

Bornstein, R. F., \& D'Agostino, P. R. (1994). The attribution and discounting of perceptual fluency: Preliminary tests of a perceptual fluency/ attributional model of the mere exposure effect. Social Cognition, 12, 103-128. doi:10.1521/soco.1994.12.2.103

Brickman, P., Meyer, P., \& Fredd, S. (1975). Effects of varying exposure to another person with familiar or unfamiliar thought processes. Journal of Experimental Social Psychology, 11, 261-270. doi:10.1016/S00221031(75)80026-6

Brockner, J., \& Swap, W. C. (1976). Effects of repeated exposure and attitudinal similarity on self-disclosure and interpersonal attraction. Journal of Personality and Social Psychology, 33, 531-540. doi: 10.1037/0022-3514.33.5.531

Canevello, A., \& Crocker, J. (2010). Creating good relationships: Responsiveness, relationship quality, and interpersonal goals. Journal of Personality and Social Psychology, 99, 78-106.

Clark, H. H. (1996). Using language. Cambridge, England: Cambridge University Press. doi:10.1017/CBO9780511620539

Clark, H. H., \& Brennan, S. A. (1991). Grounding in communication. In L. B. Resnick, J. M. Levine, \& S. D. Teasley (Eds.), Perspectives on socially shared cognition (pp. 127-149). Washington, DC: American Psychological Association. doi:10.1037/10096-006

Clark, L. A., \& Watson, D. (1988). Mood and the mundane: Relations between daily life events and self-reported mood. Journal of Personality and Social Psychology, 54, 296-308. doi:10.1037/0022-3514.54.2.296

Clark, M. S., \& Mills, J. (2001). Behaving in such a way as to maintain and enhance relationship satisfaction. In J. H. Harvey \& A. E. Wenzel (Eds.), Relationship maintenance and enhancement (pp. 13-26). Mahwah, NJ: Erlbaum.

Collins, N. L., \& Miller, L. C. (1994). Self-disclosure and liking: A meta-analytic review. Psychological Bulletin, 116, 457-475. doi: 10.1037/0033-2909.116.3.457

Curtis, R. C., \& Miller, K. (1986). Believing another likes or dislikes you: Behaviors making the beliefs come true. Journal of Personality and Social Psychology, 51, 284-290. doi:10.1037/0022-3514.51.2.284

Denrell, J. (2005). Why most people disapprove of me: Experience sampling in impression formation. Psychological Review, 112, 951-978. doi:10.1037/0033-295X.112.4.951

Druckman, D., \& Broome, B. J. (1991). Value differences and conflict resolution: Familiarity or liking? Journal of Conflict Resolution, 35, 571-593. doi:10.1177/0022002791035004001

Eastwick, P. W., \& Finkel, E. J. (2008). Sex differences in mate preferences revisited: Do people know what they initially desire in a romantic partner? Journal of Personality and Social Psychology, 94, 245-264. doi:10.1037/0022-3514.94.2.245

Eastwick, P. W., Finkel, E. J., \& Eagly, A. H. (2010). When and why do people fail to use their ideal partner preferences when selecting and retaining a romantic partner? Manuscript submitted for publication.

Ebbesen, E. B., Kjos, G. L., \& Konecni, V. J. (1976). Spatial ecology: Its effects on the choice of friends and enemies. Journal of Experimental Social Psychology, 12, 505-518. doi:10.1016/0022-1031(76)90030-5

Festinger, L., Schachter, S., \& Back, K. (1950). Social pressures in informal groups: A study of human factors in housing. Stanford, CA: Stanford University Press.

Floyd, K. (2006). Communicating affection. New York, NY: Cambridge University Press. doi:10.1017/CBO9780511606649

Frost, J. H., Chance, Z., Norton, M. I., \& Ariely, D. (2008). People are experience goods: Improving online dating with virtual dates. Journal of Interactive Marketing, 22, 51-61. doi:10.1002/dir.20107

Funder, D. C. (1995). On the accuracy of personality judgment: A realistic approach. Psychological Review, 102, 652-670. doi:10.1037/0033295X.102.4.652

Funder, D. C., \& Colvin, C. R. (1988). Friends and strangers: Acquaintanceship, agreement, and the accuracy of personality judgment. Journal of Personality and Social Psychology, 55, 149-158. doi:10.1037/00223514.55.1.149

Gollwitzer, P. M., \& Bayer, U. (1999). Deliberative versus implemental mindsets in the control of action. In S. Chaiken \& Y. Trope (Eds.), Dual-process theories in social psychology (pp. 403-422). New York, NY: Guilford Press.

Hardin, C. D., \& Higgins, E. T. (1996). Shared reality: How social verification makes the subjective objective. In R. M. Sorrentino \& E. T. Higgins (Eds.), Handbook of motivation and cognition (pp. 28-84). New York, NY: Guilford Press.

Harrison, A. A. (1969). Exposure and popularity. Journal of Personality, 37, 359-377. doi:10.1111/j.1467-6494.1969.tb01750.x

Heine, S. J., \& Renshaw, K. (2002). Interjudge agreement, selfenhancement, and liking: Cross-cultural divergences. Personality and Social Psychology Bulletin, 28, 578-587. doi:10.1177/0146167202288002

Ickes, W. (2009). Strangers in a strange lab: How personality shapes our initial encounters with others. New York, NY: Oxford University Press.

Kelley, H. H., Berscheid, E., Christensen, A., Harvey, J. H., Huston, T. L., Levinger, G., . . Peterson, D. R. (1983). Close relationships. New York, NY: Freeman.

Kenny, D. A. (1994). Interpersonal perception: A social relations analysis. New York, NY: Guilford Press.

Kenny, D. A., Kashy, D. A., \& Cook, W. L. (2006). Dyadic data analysis. New York, NY: Guilford Press.

Kruglanski, A. W., Thompson, E. P., Higgins, E. T., Atash, M. N., Pierro, A., Shah, J. Y., \& Spiegel, S. (2000). To "do the right thing" or to "just do it": Locomotion and assessment as distinct self-regulatory imperatives. Journal of Personality and Social Psychology, 79, 793-815. doi:10.1037/0022-3514.79.5.793

Kumashiro, M., Rusbult, C. E., Finkenauer, C., \& Stocker, S. (2007). To think or to do: Assessment orientation, locomotion orientation, and the Michelangelo phenomenon. Journal of Social and Personal Relationships, 24, 591-611. doi:10.1177/0265407507079261

Lee, A. Y. (2001). The mere exposure effect: An uncertainty reduction explanation revisited. Personality and Social Psychology Bulletin, 27, 1255-1266. doi:10.1177/01461672012710002

Letzring, T. D., Wells, S. M., \& Funder, D. C. (2006). Quantity and quality of available information affect the realistic accuracy of personality judgment. Journal of Personality and Social Psychology, 91, 111-123. doi:10.1037/0022-3514.91.1.111

MacKinnon, D. P., Lockwood, C. M., \& Williams, J. (2004). Confidence limits for the indirect effect: Distribution of the product and resampling methods. Multivariate Behavioral Research, 39, 99-128. doi:10.1207/ s15327906mbr3901_4

Mikulincer, M., \& Shaver, P. (2007). Attachment patterns in adulthood: Structure, dynamics, and change. New York, NY: Guilford Press.

Miller, L. C., \& Read, S. J. (1987). Why am I telling you this? Selfdisclosure in a goal-based model of personality. In V. J. Derlega \& J. H 
Berg (Eds.), Self-disclosure: Theory, research, and therapy (pp. 35-58). New York, NY: Plenum Press.

Mita, T. H., Dermer, M., \& Knight, J. (1977). Reversed facial images and the mere-exposure hypothesis. Journal of Personality and Social Psychology, 35, 597-601. doi:10.1037/0022-3514.35.8.597

Montoya, R. M., Horton, R. S., \& Kirchner, J. (2008). Is actual similarity necessary for attraction? A meta-analysis of actual and perceived similarity. Journal of Social and Personal Relationships, 25, 889-922. doi: $10.1177 / 0265407508096700$

Moreland, R. L., \& Beach, S. R. (1992). Exposure effects in the classroom: The development of affinity among students. Journal of Experimental Social Psychology, 28, 255-276. doi:10.1016/0022-1031(92)90055-O

Moreland, R. L., \& Zajonc, R. B. (1982). Exposure effects in person perception: Familiarity, similarity, and attraction. Journal of Experimental Social Psychology, 18, 395-415. doi:10.1016/0022-1031(82)90062-2

Murray, S. L., Holmes, J. G., Bellavia, G., Griffin, D. W., \& Dolderman, D. (2002). Kindred spirits? The benefits of egocentrism in close relationships. Journal of Personality and Social Psychology, 82, 563-581. doi:10.1037/0022-3514.82.4.563

Nahemow, L., \& Lawton, M. P. (1975). Similarity and propinquity in friendship formation. Journal of Personality and Social Psychology, 32, 205-213. doi:10.1037/0022-3514.32.2.205

Newcomb, T. M. (1961). The acquaintance process. New York, NY: Holt, Rinehart \& Winston.

Norton, M. I., Frost, J. H., \& Ariely, D. (2007). Less is more: The lure of ambiguity, or why familiarity breeds contempt. Journal of Personality and Social Psychology, 92, 97-105. doi:10.1037/0022-3514.92.1.97

Orive, R., \& Gerard, H. B. (1987). The familiar stimulus as a reducer of anxiety: An experimental study. Journal of Social and Clinical Psychology, 5, 330-338.

Oskamp, S. (1965). Overconfidence in case-study judgments. Journal of Consulting Psychology, 29, 261-265. doi:10.1037/h0022125

Parker-Rees, R. (2007). Liking to be liked: Imitation, familiarity and pedagogy in the first years of life. Early Years: An International Journal of Research and Development, 27, 3-17.

Pennebaker, J. W., Francis, R. J., \& Booth, M. E. (2001). Linguistic Inquiry and Word Count (LIWC). Mahwah, NJ: Erlbaum.

Perlman, D., \& Oskamp, S. (1971). The effects of picture content and exposure frequency on evaluations of Negroes and Whites. Journal of Experimental Social Psychology, 7, 503-514. doi:10.1016/00221031(71)90012-6

Pettigrew, T. F. (1998). Intergroup contact theory. Annual Review of Psychology, 49, 65-85. doi:10.1146/annurev.psych.49.1.65

Pollmann, M. M. H., \& Finkenauer, C. (2009). Investigating the role of two types of understanding in relationship well-being: Understanding is more important than knowledge. Personality and Social Psychology Bulletin, 35, 1512-1527. doi:10.1177/0146167209342754

Preacher, K. J., \& Hayes, A. F. (2004). SPSS and SAS procedures for estimating indirect effects in simple mediation models. Behavior Research Methods, Instruments, \& Computers, 36, 717-731.

Preacher, K. J., \& Hayes, A. F. (2008). Asymptotic and resampling strategies for assessing and comparing indirect effects in multiple mediator models. Behavior Research Methods, 40, 879-891. doi:10.3758/ BRM.40.3.879

Rajecki, D. W. (1985). Predictability and control in relationships: A perspective from animal behavior. In W. Ickes (Ed.), Compatible and incompatible relationships (pp. 11-31). New York, NY: SpringerVerlag.

Reis, H. T. (2006). The Perceived Responsiveness Scale. Unpublished manuscript, University of Rochester, NY.

Reis, H. T., \& Aron, A. (2008). Love: What is it, why does it matter, and how does it operate? Perspectives on Psychological Science, 3, 80-86. doi:10.1111/j.1745-6916.2008.00065.x

Reis, H. T., Clark, M. S., \& Holmes, J. G. (2004). Perceived partner responsiveness as an organizing construct in the study of intimacy and closeness. In D. J. Mashek \& A. Aron (Eds.), Handbook of closeness and intimacy (pp. 201-225). Mahwah, NJ: Erlbaum.

Reis, H. T., \& Gable, S. L. (2003). Toward a positive psychology of relationships. In C. L. Keyes \& J. Haidt (Eds.), Flourishing: The positive person and the good life (pp. 129-159). Washington, DC: American Psychological Association. doi:10.1037/10594-006

Reis, H. T., \& Patrick, B. C. (1996). Attachment and intimacy: Component processes. In A. Kruglanski \& E. T. Higgins (Eds.), Social psychology: Handbook of basic principles (pp. 523-563). New York, NY: Guilford Press.

Reis, H. T., \& Shaver, P. (1988). Intimacy as an interpersonal process. In S. W. Duck (Ed.), Handbook of personal relationships (pp. 367-389). Chichester, England: Wiley.

Rosenthal, R., Rosnow, R. L., \& Rubin, D. B. (2000). Contrasts and effect sizes in behavioral research: A correlational approach. New York, NY: Cambridge University Press.

Sedikides, C., Campbell, W. K., Reeder, G., \& Elliot, A. J. (1999). The Relationship Closeness Induction Test. Representative Research in Social Psychology, 23, 1-4.

Segal, M. W. (1974). Alphabet and attraction: An unobtrusive measure of the effect of propinquity in a field setting. Journal of Personality and Social Psychology, 30, 654-657. doi:10.1037/h0037446

Shook, N. J., \& Fazio, R. H. (2008). Interracial roommate relationships: An experimental field test of the contact hypothesis. Psychological Science, 19, 717-723. doi:10.1111/j.1467-9280.2008.02147.x

Smith, E. R., Miller, D. A., Maitner, A. T., Crump, S. A., Garcia-Marques, T., \& Mackie, D. M. (2006). Familiarity can increase stereotyping. Journal of Experimental Social Psychology, 42, 471-478. doi:10.1016/ j.jesp.2005.07.002

Snyder, M., \& Haugen, J. (1995). Why does behavioral confirmation occur? A functional perspective on the role of the target. Personality and Social Psychology Bulletin, 21, 963-974. doi:10.1177/0146167295219010

Sprecher, S., Schwartz, P., Harvey, J., \& Hatfield, E. (2008). The BusinessOfLove.com: Relationship initiation at Internet matchmaking services. In S. Sprecher, A. Wenzel, \& J. Harvey (Eds.), Handbook of relationship initiation (pp. 249-265). New York, NY: Psychology Press.

Stasser, G., Taylor, L. A., \& Hanna, C. (1989). Information sampling in structured and unstructured discussions of three and six-person groups. Journal of Personality and Social Psychology, 57, 67-78. doi:10.1037/ 0022-3514.57.1.67

Swann, W. B., Jr. (1990). To be adored or to be known: The interplay of self-enhancement and self-verification. In R. Sorrentino \& E. T. Higgins (Eds.), Handbook of motivation and cognition (Vol. 2, pp. 408-448). New York, NY: Guilford Press.

Swann, W. B., Jr., \& Gill, M. J. (1997). Confidence and accuracy in person perception: Do we know what we think we know about our relationship partners? Journal of Personality and Social Psychology, 73, 747-757. doi:10.1037/0022-3514.73.4.747

Triandis, H. C., Bontempo, R., Villareal, M. J., Asai, M., \& Lucca, N. (1988). Individualism and collectivism: Cross-cultural perspectives on self-ingroup relationships. Journal of Personality and Social Psychology, 54, 323-338. doi:10.1037/0022-3514.54.2.323

Walster, E., Aronson, V., Abrahams, D., \& Rottman, L. (1966). Importance of physical attractiveness in dating behavior. Journal of Personality and Social Psychology, 4, 508-516. doi:10.1037/h0021188

Wieselquist, J., Rusbult, C. E., Foster, C. A., \& Agnew, C. R. (1999). Commitment, pro-relationship behavior, and trust in close relationships. Journal of Personality and Social Psychology, 77, 942-966.

Winkielman, P., Schwarz, N., Fazendiero, T., \& Reber, R. (2003). The hedonic marking of processing fluency: Implications for evaluative judgment. In J. Musch \& K. C. Klauer (Eds.), The psychology of evaluation: Affective processes in cognition and emotion (pp. 189-217). Mahwah, NJ: Erlbaum. 
Wolf, A. P. (1995). Sexual attraction and childhood association: A Chinese brief for Edward Westermarck. Stanford, CA: Stanford University Press.

Zajonc, R. B. (1965, July 16). Social facilitation. Science, 149, 269-274. doi:10.1126/science.149.3681.269
Zajonc, R. B. (1968). Attitudinal effects of mere exposure. Journal of Personality and Social Psychology, 9, 1-27. doi:10.1037/h0025848

Zajonc, R. B. (2001). Mere exposure: A gateway to the subliminal. Current Directions in Psychological Science, 10, 224-228. doi:10.1111/14678721.00154

\section{Appendix}

\section{Twelve-Item Perceived Responsiveness Scale}

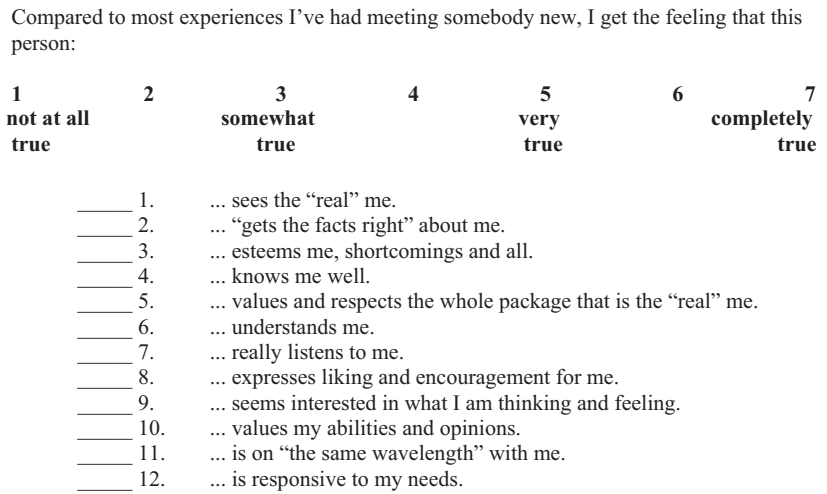

Received June 11, 2010

Revision received December 17, 2010

Accepted December 20, 2010 